\title{
Who benefits from the wisdom of the crowd in crowdfunding? Assessing the benefits of user-generated and mass personal electronic word of mouth in computer-mediated financing
}

March 04, 2018

\author{
Jermain Kaminski ${ }^{1 *}$, Christian Hopp ${ }^{2 *} \&$ Christian Lukas $^{3}$
}

\begin{abstract}
In this work, we explore the link between electronic word of mouth in the form of user-generated content (online forum interactions on Kickstarter) and through mass personal communication (sharing information through Facebook) on the performance of crowdfunding campaigns. Our formal theoretical model implies that the efficiency of electronic word of mouth is determined by the quality of the underlying crowdfunding campaign. Using a sample of 572 project observations, we test our theoretical predictions in cross-sectional logistic regression and ancillary Granger analyses. Our results highlight the interactive contingency of social media engagement and the success of the crowdfunding campaign. While a higher quality campaign is benefitting from user generated electronic word of mouth (online comments), the returns are diminishing. For mass personal electronic word of mouth (Facebook shares), we even find a reverse causal effect. Social media activity follows a successful campaign, but does not affect the success probability of the campaign. Crowdfunding campaigns need to approach their social media activities with a certain note of sensitivity to achieve the objective of successfully reaching their campaign goal.
\end{abstract}

\section{Introduction}

In recent years, crowdfunding arose as a new type of financing for entrepreneurial ventures. In reward-based crowdfunding, many small investors contribute capital to pre-buy a to-bedeveloped product. Crowdfunding platforms, such as Kickstarter, support entrepreneurs in several ways. First, they offer financing in the very early, exploratory phase. Second, crowdfunding platforms offer direct interaction with potential end users. Through feedback and online communication, the crowd may prove useful in reshaping and improving the product. Third, through a crowdfunding platform, entrepreneurs not only attract potential customers and early-stage financiers, but also obtain visibility and press coverage, sending signals to other potential backers.

\footnotetext{
${ }^{1}$ Chair for Technology Entrepreneurship (TEN), RWTH Aachen University, kaminski@time.rwth-aachen.de

${ }^{2}$ Chair for Technology Entrepreneurship (TEN), RWTH Aachen University, hopp@time.rwth-aachen.de [corresponding author].

${ }^{*}$ The authors like to thank the German Federal Ministry of Education and Research for supporting the project within the framework of the exploratory project "InnoFinance" (01IO1702).

${ }^{3}$ Chair for Controlling, University of Jena, christian.lukas@uni-jena.de
} 
In this new era of computer-mediated financing, a question arises as to what benefit the crowd brings beyond the mere provision of capital and for whom these intangible resources are beneficial. Crowdfunding not only provides capital but also a broad array of electronic word of mouth channels that may help to reduce uncertainty over products being financed. Sharing personal views in online interactions might overcome uncertainty and the wide availability of electronic word of mouth could help to answer questions about new technology feasibility and viability (Gable and Reis, 2010; Zell and Moeller, 2017). As such, the collection of backers may reduce the risk of being invested in lower quality campaigns that may not live up to the promised product characteristics (Mollick, 2014). Our research question therefore addresses whether and to which extent crowdfunding campaign creators benefit from engaging in online communications and social media interactions.

Early stage financing is especially noisy, with many technologies that are not ripe for the market yet, and many firms failing. For the potential backers in crowdfunding it is difficult to assess which technology or venture will succeed (Ewens and Rhodes-Kropf, 2015; Kerr, Lerner, and Schoar, 2011). Hence, the "social sharing of positive events" (Gable and Reis, 2010: 198) through mass personal communication (sharing information for friends on Facebook or similar media) or user generated content (online interactions on the computer-mediated financing platform) might engage weak ties and hence, creates awareness of new products developed. Related research supports the role of signals that reduce uncertainty around new companies and technologies in noisy and ambiguous environments (Certo, 2003; Plummer, Allison and Connelly, 2016; Arthurs, Busenitz, Hoskisson, and Johnson, 2009). Research on electronic word of mouth in various social media outlets (ranging from blogs to Youtube channels) reports social interactions as beneficial for knowledge exchanges and sharing among peer consumers (Rozzel et al., 2014). Thus, there are many new ways in which crowdfunding platforms help to lift the shadow of the future and convey valuable signals about technological feasibility and likely market acceptance.

In the following, we therefore explore the link between electronic word of mouth in the form of user-generated content (online forum interactions on Kickstarter) and through mass personal communication (sharing of the link to the crowdfunding campaign webpage through Facebook) on the performance of crowdfunding campaigns. Our formal theoretical analysis suggests that the positive effect of user-generated content through online interactions is conditional on the quality of the campaign. Yet, we also show that mass personal communication (such as the sharing of campaign links combined with personal views on Facebook) is less effective than user generated content. 
As suggested by our theoretical model, electronic word of mouth may not necessarily translate into higher probabilities of reaching the campaign goal successfully; rather a higher frequency of interaction (user-generated content through comment interaction) is important for signaling to other potential investors. In addition, our results suggest an interactive contingency, in which the beneficial effect of user-generated content hinges on the characteristics of the campaign. Those campaigns that are either too low in terms of their perceived campaign quality fail to capitalize on the benefits the crowd interaction may bring about. Yet, the beneficial effect of user-generated content is diminishing for high quality campaigns as well. With an increase in perceived campaign quality, crowd interactions may translate into lower and lower probabilities of reaching the campaign goal successfully.

We explore the "wisdom of the crowd" angle in crowdfunding and emphasize interpersonal connections and communication intensity. We thus extend prior work on consumer contributions to crowdfunding by highlighting the knowledge exchange and collaboration part that makes crowdfunding worth the while. Similarly, we believe that our research informs a recent debate about the ubiquitous assumption of monotonic linear relationship between predictor and criterion variables (Pierce and Aguinis, 2013). Although some strategies provide performance benefits, these benefits might be subject to diminishing returns. Thus, we see our examination of crowdfunding campaign characteristics and the conditionality of the positive effects of user-generated content as providing an important contribution to the literature.

We proceed as follows. In section two we present our theoretical model and derive the testable hypotheses. In section three we present the dataset, variables and methods. In section four we present the results. Section five discusses the findings and section six concludes.

\section{Theoretical Background and Hypotheses}

\subsection{Related Literature and Theoretical Background}

In crowdfunding, many unanticipated situations or circumstances may endanger project success. From a backers' perspective the unforeseeable circumstances bear the risk that campaign objectives cannot be realized (Mollick and Kuppuswamy, 2014). Campaigns may promise quality features that they cannot live up to. Because of hard-to-measure and hard-tocommunicate project risks and benefits, potential backers are plagued by information asymmetry. This is especially problematic, as campaign founders may not have an incentive to fully (and truly) reveal their characteristics as the gains from falsely claiming high quality (and reaching the campaign goal) outweigh the losses suffered in the event of detection (as there are 
limited contractual arrangements; Cumming et al., 2016). For example, in certain campaigns, users discuss various technical glitches and product features that differ from the promised version of the product during the campaign. The digital router Torch (total of 1,030 backers and contributions summing up to 162,401 USD) had to announce that the promised router architecture was malfunctioning and could (at best) only work as an access point. ${ }^{4}$ Hence, despite promises made in the campaigns it is extremely difficult to distinguish more and less able founders upfront.

Taken together, the potential backer is at an informational disadvantage about the quality of the campaign (and the campaign founder characteristics) and possesses less information than the campaign founder. However, the potential backer making the investment decision may use additional observable information to infer the founder's or the project's quality. Such a situation conforms to the typical setup analyzed in signaling theory: There is information asymmetry between contracting parties, and it can be reduced by signals which are observable and known in advance (Certo et al., 2001; Certo, 2003; Spence, 1973).

To create an incentive to invest potential backers need to develop trust into the competence of the campaign founder to deliver on their technical promise to reduce the perceived performance risk. In crowdfunding, third party signals (for example from prior backers) may complement the underlying information provided in the campaign (Plummer, Allison and Connelly, 2016). Backers with an interest in and knowledge of the complexity of the product may then attest to the viability of the project at hand.

In crowdfunding, we are arguing that communication signals can be emitted through electronic word of mouth. Electronic word of mouth allows users to share viewpoints and lets potential customers assess merits (or demerits) of products (Hussain et al., 2017). After having read the provided information, the shared experiences may affect customer's buying behavior and assessment in the selection of products. These forms of communication offer advice (or feedback) and may provide needed guidance to lift the shadow of potential backer uncertainty (Rozzell et al., 2014).

Sharing information on Facebook (such as the link to the crowdfunding campaign on Kickstarter) is considered an example of mass personal communication (O'Sullivan and Carr, 2017), where information circle in one's own social network and may eventually reach strong and weak ties alike. Yet, the remoteness in sharing may create lower receptivity at the receivers

\footnotetext{
${ }^{4}$ https://www.kickstarter.com/projects/mytorch/torch-a-simple-router-for-digital-parenting/description (accessed 20th December 2017).
} 
end (Zell and Moeller, 2017). While information that is shared on Facebook might be available for other friends only, information contributed on the crowdfunding platform itself, may have larger reach (and likely reach other potential backers). Comments on computer-mediated financing platforms, such as Kickstarter, are examples of user-generated forms of electronic word of mouth. User generated information facilitates support through online interactions and can take the form of online support groups (Walther and Boyd, 2002) or personal blogs (Rains and Keating, 2011). Posting comments on a platform like Kickstarter gives individual backers the opportunity to access disparate and geographically distant and likely disparate social networks for support (Agrawal, Catalini, and Goldfarb, 2015). Hence, the intensity of signals send through either mass personal communication or user-generated content may differ.

Both the emission of information through computer-mediated financing platforms and social media channels and the intensity with which they are emitted are important for potential backers to attest to the quality of the underlying crowdfunding campaigns. Without the aggregation of signals, it is difficult to gauge the quality of an entrepreneur's characteristics and actions, and especially to understand the potential of radical new innovation and technologies (Plummer, Allison and Connelly, 2016). Our model would suggest a positive dynamic interaction between the computer-mediated communication and a project's potential to successfully reach the campaign goal (Plummer, Allison and Connelly, 2016). Yet, we also show that the positive effect of communication is conditional on the communication intensity and the perceived quality of the underlying project.

\subsection{Model Derivation}

The following model is based on Lukas' (2007) beta distribution model of qualification given unknown ex ante ability. ${ }^{5}$ A crowdfunding campaign owner has an ex ante probability $E(p)=$ $\frac{\alpha}{\alpha+\beta}, \alpha, \beta>0$, of successfully raising capital through the crowd. The distribution $f(p)$ is a beta distribution with parameters $\alpha$ and $\beta$. Since $0<E(p)<1$, the mean of the distribution can be thought of as the initial chance that the campaign founder will reach his campaign goal.

Let $\alpha$ indicate the factors that appear to be helpful to reach the campaign goal. We can interpret the parameter very generally as representing those project (or entrepreneur) characteristics that

\footnotetext{
${ }^{5}$ This Beta distribution model goes back to Pearson (1925) and Skellam (1948) and has been applied in various fields, e.g. marketing, especially in stochastic models of buying behavior (Massy et al. (1970), pp. 61ff). See Lee and Lio (1999) for further applications and references.
} 
relate to the potential success of the campaign. ${ }^{6}$ In contrast, $\beta$ is assumed to represent project characteristics that are or appear to be detrimental to project success. In this light, we can interpret the parameter very generally as "hidden characteristics" or the "uncertainty of the project's true potential". This resembles the notion of project characteristics detrimental to project success and both factors become part of the parameter $\beta$. The more information in the campaign that potential backers can infer about $\alpha$ the more likely they are to invest, and the more likely is the campaign to reach its goal. Similarly, the more uncertainty about the project exists, the less likely are potential backers to contribute, and the less likely will the campaign reach its goal.

Yet, in crowdfunding, backers have an incentive to invest into the campaign because they envision future benefits from the product that can only be realized when others join the cause. In crowdfunding, the person who already has pledged money to a campaign can also chose to voluntarily provide information (for example through sharing information through social media, e.g. making the crowdfunding platform link visible to Facebook friends) about his reasons to pledge (or the event itself), and to decide doing it publicly (for example through the crowdfunding platform: to everyone interested in the campaign). The communication is freely accessible (i.e., observable), and can be understood in advance for other potential backers (Certo et al., 2001, Connelly et al., 2011). In doing so, the crowd may help close the gap between what outsiders know and what they want to know (Bergh, Connelly, Ketchen, \& Shannon, 2014). Hence, this electronic word of mouth by the crowd may validate the authenticity of a campaign and likely technology, and can confirm the value of previous actions undertaken through a combined crowd assessment, and may reduce uncertainty and ambiguity on the part of other potential backers (Arthurs, Busenitz, Hoskisson, \& Johnson, 2009). When these potential backers observe that a certain new technology has received widespread community support, they may interpret it as an indicator of the true venture viability and technological feasibility in this field, which eventually creates competence trust into the founder.

By providing an additional publicly observable signal on the project, uncertainty about the project's prospects may be resolved for other potential backers. Theoretically, signaling support publicly by backers leads to a change in parameters and hence to a different estimate of the probability that the project will be successful. Formally, the parameters $\alpha$ and $\beta$ change to

$$
\alpha_{1}=\alpha+i h
$$

\footnotetext{
${ }^{6}$ Related work shows that information about the project, the founder, or the technology could be relevant here (Bergh, Connelly, Ketchen, \& Shannon, 2014). We elaborate in more detail on the factors impacting the quality of the project in the empirical section.
} 


$$
\beta_{1}=\beta+(1-i) h
$$

leading to

$$
E\left(p_{1}\right)=\frac{\alpha_{1}}{\alpha_{1}+\beta_{1}}=\frac{\alpha+i h}{\alpha+\beta+h}
$$

To provide intuition for the change in parameters, note that with the public voicing of support (through electronic word of mouth) $h$ the parameter $\alpha$ increases by $i \cdot h, 0 \leq i \leq 1$, where $i$ is a measure of the project's perceived quality. Hence, the public voicing of support signals about underlying project quality. Ceteris paribus, the higher the potential quality $i$ of a project is the more valuable is the publicly observable signal $h$ emitted to both the project's success itself and to the potential backer (who would get a higher estimate for the project's chance to succeed). ${ }^{7}$ We therefore formulate hypothesis 1 :

Hypothesis 1: Electronic word of mouth by crowdfunding backers will increase the chances of a crowdfunding campaign to reach its campaign goal.

Besides the possibly advantageous effect of signaling through publicly voicing support, the intensity of the interaction is likely to affect the probability of reaching the campaign goal. With regard to the signaling effect of publicly voiced support, more interaction (user-generated content as opposed to mass personal communication) certainly helps to improve the signal as it helps to illumine the nature of the project further. Hence, backers may choose to engage in observable conversations with the founder or other backers may similarly voice their own support. In this context, especially the aggregation of information is important for the potential backers.

A higher signaling intensity by the community (for example, discussions and a collection of opinions) presents a stronger signal than a once-off engagement for a single signaling activity (say for example, a lone supporter voicing his support through a social media channel). The provision and aggregation of repetitive signals fosters differentiation between projects and avoids rendering an initial communication signal erroneous (Janney \& Folta, 2003). Hence, we would argue that the user generated comments on computer-mediated financing platforms make the crowd's assessment more noticeable; that is, the crowd helps 'pierce the fog of futurity,' reduces the uncertainty of underlying information, and eventually resolves ambiguity.

\footnotetext{
${ }^{7}$ The model also accounts for the fact that signaling can naturally go both ways. While attesting to a projects quality may be helpful, afterthoughts and criticisms may be raised similarly in public. To allow for the possibility that comments reduce the chance that the campaign goal will be reached the parameter $\beta$ is affected by the comment here as well; specifically we assume that $\beta$ increases by $(1-i) h$. Receiving a comment from an investor about a project that may link to unwanted product characteristics, for example where $i \rightarrow 0$, may cast doubt on the viability (or attractiveness) of the project and as a consequence only $\beta$ increases while $\alpha$ remains by and large unchanged. The model thus cannot only be used to model the benefits of publicly available signals, but also presents potential to explore downsides of negative signals send.
} 
Consequentially, the user generated electronic word of mouth makes the individual communication sent relevant, and allows to make more accurate assessments of new technologies. Repeated interactions should increase chances to reach the campaign goal.

Let $0<t<1$ simply be a measure for the number of times the contributors can publicly voice support collectively. This interaction intensity variable influences parameter $\alpha_{1}-$ the aggregate of conducive characteristics for reaching the campaign goal - and $\beta_{1}$ - the aggregate of characteristics detrimental to (or lacking) for a successful campaign. Given that the interaction intensity is inextricably linked to the public signal $h$, its effect on parameters is modeled in similar fashion as the public signal $h$ :

$$
\begin{aligned}
& \alpha_{2}=\alpha_{1}(t)=\alpha+i \cdot t \cdot h \\
& \beta_{2}=\beta_{1}(t)=\beta+(1-i \cdot t) h
\end{aligned}
$$

and

$$
E\left(p_{2}\right)=\frac{\alpha_{2}}{\alpha_{2}+\beta_{2}}=\frac{\alpha+i t h}{\alpha+\beta+h}
$$

The following relations are easily verified:

$$
\begin{aligned}
& \frac{\partial}{\partial h} E\left(p_{2}\right) \quad=\frac{i t(\alpha+\beta)-\alpha}{(\alpha+\beta+h)^{2}} \gtreqless 0 \Leftrightarrow i t(\alpha+\beta)-\alpha \gtreqless 0 \\
& \frac{\partial^{2}}{\partial h^{2}} E\left(p_{2}\right) \quad=-\frac{2[i t(\alpha+\beta)-\alpha]}{(\alpha+\beta+h)^{3}} \gtreqless 0 \Leftrightarrow i t(\alpha+\beta)-\alpha \lesseqgtr 0
\end{aligned}
$$

The derivative in (3) indicates when the public signal $h$ leads to a higher probability of reaching the campaign goal. If the perceived quality $i$ of the project is high enough, the founder will benefit from the backer's additional emitted public signal; the backer's signal is good news about the project. In other words, publicly voiced support is a valuable signal that helps to better estimate the probability of success and the revised estimate is higher than the ex ante estimate. ${ }^{8}$ Hence, when campaign quality is high, intense electronic word of mouth can help to convey positive aspects of the campaign.

Turning to the effect of signaling intensity it is straightforward to see that

$$
\frac{\partial}{\partial t} E\left(p_{2}\right)=\frac{h i}{\alpha+\beta+h}>0
$$

\footnotetext{
${ }^{8}$ For projects with a very low level of perceived quality and/or a low signaling intensity, the derivative in (3) is negative, i.e. $i t(\alpha+\beta)-\alpha<0$. In this case the additional signal send through publicly voiced support is also valuable but it is bad news so that the revised estimated probability is lower than the ex-ante estimated probability.
} 
the higher the intensity of the communication taking place, the higher the likelihood of reaching the campaign goal. Our interpretation is that the collective voicing taking place in user generated commentaries and forum interactions increases competence trust and that in turn reduces perceived performance risk; and in doing so, it has a stronger effect than the individual voicing through mass personal communication (Das and Teng, 2001). This is in line, with previous work that documents that the efficacy of social support strongly hinges on equity; the communities' willingness to reciprocate. In online interactions, individuals tend to provide significant, yet low cost, social support by posting brief comments that may help others (Rozzell et al., 2014). This way, "consumers become a new source of competence" (Prahalad and Ramaswamy, 2000: 79). Since the derivative in (5) is unambiguous, a higher signaling intensity is beneficial for both low quality projects and high quality projects. This leads to:

Hypothesis 2: A higher communication intensity in electronic word of mouth by crowdfunding backers will increase the chances of a crowdfunding campaign to reach its campaign goal.

Yet, when considering (3) and (4) we conclude that if additional electronic word of mouth increases the probability to reach the campaign goal it will do so at a decreasing rate: if the derivative in (3) is positive, the derivative in (4) is negative. And the rate at which the benefit of additional communication decreases is affected by the project's perceived quality; a higher quality is associated with a faster decreasing rate. Consequently, we formulate

Hypothesis 3: The higher the perceived quality of a campaign the lower will be the positive effect of additional electronic word of mouth.

\section{Data and Methods Data Description}

\subsection{Dataset}

We draw our data from the crowdfunding platform Kickstarter, a global crowdfunding platform with the mission to "help bring creative projects to life". ${ }^{9}$ It acts as an intermediary between potential funders and creators of projects, yet does not claim ownership of projects. So called backers (individual funders) can contribute money (starting from a few USD) and are offered rewards in return for their contribution.

\footnotetext{
${ }^{9}$ https://www.kickstarter.com/charter; accessed November $13^{\text {th }} 2016$.
} 
The use of Kickstarter helps to test our theoretical framework along several dimensions. Firstly, having raised more than 3bn USD since its inception on April 28, 2009 till October 31, 2016, Kickstarter is the world's largest online crowdfunding platform. Secondly, due to this wide acceptance it is representative of projects from various technical domains seeking external funding from the crowd (Mollick and Nanda, 2015; Mollick, 2014). Lastly, Kickstarter campaigns see a strong interaction between the backer network, the founder, and the online community as an intermediary platform. It therefore ensures that we can test the theorized effects against this background. Though, creators may apply for funding in fifteen different categories (from cultural to technology fields) this work is only focused on projects within the product categories "Technology" and "Product Design".

In order to develop insights into temporal project dynamics, we implemented a daily crawler for all projects launched on Kickstarter between 1st September 2015 and 31st of October 2015 (domiciled in the US) from their first until the last campaign day. The acquired sample is restricted to campaigns that involve a "hardware" type product. We follow this procedure for several reasons. For one, this sample and time frame ensures the representativeness of our survey and analysis of crowdfunding activity. In doing so, we can track campaigns over the course of their development, without ex-ante knowledge of eventual success or failure. Thus, by no means can we condition or select on the dependent variable and potential survivorship biases are minimized. Hence, our data is also longitudinal with daily indications of project evolution which allows for causal inferences between campaign characteristic and chosen campaign outcome variables. All information for the dependent variables (success and amount pledged) are scraped directly from the Kickstarter website. The amount pledged is scraped daily and thus allow us to track the development of campaign and to infer the final outcome. For the key independent variables of interest, we also scraped the number of comments and the Facebook shares on a daily basis.

To assess the campaign quality and other control variables, we recruited a total of 27 individuals to elicit their ratings about key dimensions. Evaluations were done through Google Forms. The URL links to simulated project pages were randomly assigned. ${ }^{10}$ Responders could access a copy of the original website data through a password protected website simulation. That is we mimic initial starting conditions and respondents cannot observe the outcome for the campaign.

\footnotetext{
${ }^{10} \mathrm{We}$ randomly assigned 70 projects to all raters. Out of these 70 project URLs, we expected at least 50 valid "consumer hardware" projects. In terms of selection, there were at least 5 failed projects (lower $25 \%$ quartile of under-funded projects), 5 very successful projects (higher $25 \%$ quartile of over-funded projects), and 60 projects that received more than 1 USD amount pledged randomly assigned. All respondents had to evaluate the same 10 projects and at minimum two respondents had to rate 40 randomly assigned projects.
} 
The final browser interface of a Kickstarter campaign appeared just like its original version, with the only difference that we reset the total amount pledged, the number of backers, updates and comments to zero in order to avoid any responder bias. Our sample for the regressions comprises 572 project observations (of which 153 projects appear multiple times because they have been rated by several individuals).

\subsection{Methods}

Our analysis comprises two complementary approaches. We begin with a cross-sectional analysis and complement this analysis with a Granger causality approach that allows for more insights into temporal effects.

\section{Cross-Sectional Analysis}

We first provide the results on the main and conditional effects using a cross-sectional analysis. We present a logit (using campaign success as dependent variable) with the number of comments and the Facebook shares as the predictor variable (plus controls). To test for the moderating effect of campaign quality, we split the sample for three different tertiles of the three campaign quality variables and depict coefficient estimates and standard errors separately. ${ }^{11}$ In doing so, we estimate one main regression using the full sample and then split the regressions for different levels of the campaign quality variables to see if and to which extent coefficients may differ. We refer to the statistical significance of each coefficient in the different models and draw conclusions with respect to our hypotheses. ${ }^{12}$

\section{Ancillary Method - Granger Causality}

To test our hypotheses empirically we are interested in the forecasting power of one variable on another, in particular, whether and in which direction daily comments, Facebook shares, and the amount pledged on Kickstarter co-evolve and whether or not one time-series is predictive of the other. While we may find suggestive evidence in the cross-sectional analysis, reverse causalities may still be affecting our results. In testing for a causal relation between our predictor variables and our dependent variables, we therefore also rely on the widely used concept of

\footnotetext{
${ }^{11}$ We use tertiles here to indicate low, medium, and high levels. In fact, projects are very rarely rated as 7 on the scales (only 26 observations). Hence, we grouped the tertiles into $1 / 2,3 / 4$, and 5/6/7. This results in the following distribution of observations (not accounted for missing values in other explanatory variables) across the tertiles $1^{\text {st }}=194,2^{\text {nd }}=215,3^{\text {rd }}=195$. Given the equal size of the categories, they are also reasonably comparable

${ }^{12}$ With respect to comparing statistically significant and non-significant coefficients, we follow the extant literature on comparing coefficients within binary dependent variable models. Hoetker (2007: 338), for example, notes that "If the model is estimated separately for each group, the researcher can - at a minimum -compare the statistical significance of the coefficients across groups. This is possible because the coefficients and standard errors are consistent within each group. One could report, for example, that $\mathrm{x}$ has a significant and positive impact for Group 1, but is not significant for Group 2."
} 
Granger causality that can ascertain the interaction between two time-series (Granger, 1969; Sims, 1972). The basic underlying notion here is of predictability; that is one variable is said to Granger-cause another (leaving the information set constant) if information about the past behavior of one variable can improve the forecasted behavior of another variable. In that sense, having information about one time-series of a specific variable reduces the forecast error in another variable, implying that the two variables do not evolve independently from another.

Granger causality is a statistical concept of causality that can be used to determine if one timeseries is useful in forecasting another (Granger 1969). To infer causality, cause must precede effect in time and $X_{t}$ is said to Granger-cause $Y_{t}$ if the autoregressive model of $Y_{t}$ is more accurate when based on the past values of both $X_{t}$ and $Y_{t}$ rather than $Y_{t}$ alone. That is, using the combined past values of $X_{t}$ and $Y_{t}$ (instead of using information solely from the past of $Y_{t}$ ) improves the prediction of a time series $Y_{t}$. Technically, $Y$ is (Granger-) causing $X$, when $\sigma^{2}(\mathrm{X} \mid \mathrm{U})>\sigma^{2}(\mathrm{X} \mid \overline{U-Y})$, where $\sigma^{2}(X \mid U)$ is the prediction error when all past information is included, and $\sigma^{2}(X \mid \overline{U-Y})$ is the prediction error with $Y_{t}$ excluded from the information set. The specific Granger causality test used in our model builds up on Toda and Yamamoto (1995) (TY), as all of our variables are non-stationary and potentially cointegrated. Unlike the standard Granger causality test (Granger, 1969), the TY approach enables to work with stationary and non-stationary data. Toda and Yamamoto (1995) propose a simple but robust procedure irrespective of the system's integration or cointegration properties. This procedure requires the estimation of an augmented VAR, which guarantees the asymptotic distribution of the Wald statistic (an asymptotic $\chi^{2}$-distribution). Furthermore, the TY-method avoids potential pre-test biases, as they are often observed in vector error correction models (VECM), the alternative implementation of Granger causality in the presence of time series that are integrated of different order, or cointegrated (Toda and Yamamoto, 1995).

For the analysis of causal inferences, we aggregate the comments and pledges for all projects within the different ahead of trend segments for each particular day. As such, we employ the one time series comprising the aggregate daily comments (respectively Facebook shares) and another time series comprising the aggregate daily pledges. The final sample comprises a total 104 successfully funded projects with a common campaign length of 30 days. Yet, we restrict our analysis to all data points for $\mathrm{T}-1$ as the last day of campaigns was associated with very large amounts of comments, mostly "congratulations" on successful campaigns. This structural break is further considered for our analysis and therefore all analyses are run for $\mathrm{T}=29$. In our sample, successful projects raised 8,403,710 USD in crowdfunding from 65,434 backers on 
Kickstarter. Our final data comprises 12,911 campaign comments and 172,654 Facebook shares of campaign websites.

Figure 1 shows the dynamic development of comments on Kickstarter campaigns and the number of Facebook shares of campaign websites in our sample. In particular, figure 1 highlights the common stochastic trend of comments and shares. Figure 1 reports a U-shaped effect of pledge development. Similar evidence was been reported in Althoff \& Leskovec (2015). Relatedly, Kuppuswamy and Bayus (2017) observe that support for a crowdfunding project will increase as the project funding approaches its target goal. What is important to note here, is that we do not find a trending development of pledges, such that success breeds success and creates bandwagon effects. Rather, the relationship between pledges varies across time, which allows testing whether comments may Granger-cause pledges.

[Figure 1 about here]

Toda and Yamamoto (1995) show that the standard asymptotic theory for causality testing holds if the test is carried out as follows: After inspecting the data plots and underlying trends, we use the augmented Dickey-Fuller (ADF) test (Dickey and Fuller, 1979; Dickey and Fuller, 1981), the KPSS Test (Kwiatkowski, Phillips, Schmidt and Shin, 1992), and Phillips Perron (Phillips and Perron, 1988) test, to control for stationarity and the order of integration. Finally, we conclude whether the time series are integrated at level, I(0), at first differences (I(1)), or at second order I(2). With regard to critical values by MacKinnon, Engle, and Granger (1991), we later conclude that our tested bivariate VAR are either I(1) or I(2).

In a next step, we ensure a good fit of the selected two-equation vector autoregressive (VAR) model of our log-transformed data. The lags in the VAR equations are chosen by minimizing Akaike's final prediction error' (FPE) (Akaike, 1969). In a last step of VAR model specification, we apply the Portmanteau test and further control for roots of characteristics polynomials. Latter provides information about the dynamic stability of the estimated VAR model, in terms of whether or not the inverted roots of the characteristic polynomial lie within the unit circle. Considering the dynamics of our time series, we test all time series under the assumption of a constant and trend.

After selecting the appropriate lags for the two-equation vector autoregressive (VAR) model, we apply a bi-directional Wald-test to our selected time series. For the test, we now consider the maximum order of integration (see step 1) for the augmented VAR-model as proposed by 
Toda and Yamamoto (1995). ${ }^{13}$ As our bivariate VAR are either I(1) or I(2), we test with optimum lag +1 or optimum lag +2 , respectively. The results appear in table 5. As a confirmatory analysis, we apply a Johansen cointegration test for long-run causality (Johansen 1988, Johansen and Juselius, 1990). As cointegration must imply causality in at least one direction, the results should confirm the outcomes from the TY test.

\subsection{Measurement}

\section{Dependent Variable}

In testing our theoretical framework, we employ two dependent variables. First, we measure campaign success as employed in our theoretical model above. Success is indicated by campaign creators reaching their initially stated funding goal. For Kickstarter, campaigners can choose a deadline and a minimum funding goal, yet, they will only receive the amount of money pledged if the initial funding goal has been met. We administer this variable in dichotomous form ( $1=$ Funding goal met, $0=$ failed to meet campaign goal). For a Granger causality analysis, we employ the daily amount pledged to the campaigns and aggregate these numbers for each day. This serves as our second dependent variable.

\section{Independent Variable}

To test for the impact of the online community we scraped all comments on the relevant Kickstarter campaign page and the corresponding number of Facebook shares (link to the campaign that has been shared on Facebook) that were made from the inception of the campaign until the deadline set by the creators. We employ the Facebook shares (individual supporters and backers voicing individually and not necessarily noticeable for all and sundry the link to the campaign) as a measure of individually emitted mass personal communication. While one individual comment present an individual signal, the user generated collection of comments present a higher signaling intensity available to potential backers. We therefore proxy a higher communication intensity by the collection of comments. For all campaigns, the number of

\footnotetext{
${ }^{13}$ The Toda and Yamamoto (1995) approach sometimes may suffer power in small samples (Shukur and Mantalos, 2000; Kurozumi and Yamamoto, 2000; Zapata and Rambaldi, 1997; Dolado and Lütkepohl, 1996). In particular, the MWALD test in bootstrapped experiments with $\mathrm{T}=25$ performs relatively good in identifying causality (90.4\%) but indicated lower power in correctly identifying non-causality (49.2\%) (Zapata and Rambaldi, 1997). However, Giles (1997), Chowdhury and Mavrotas (2006), as well as Mavrotas and Kelly (2001) show with similar bootstrapped simulations that the approach may work fairly well in small samples.
} 
comments and Facebook shares is available on a daily basis as well as the total (cumulative) number of comments and shares up and including the final day of the campaign. ${ }^{14}$

For the subsequent causal analysis, we aggregate the comments and pledges for all projects within the different ahead of trend categories for each particular day. Therefore, we have the aggregate daily comments and pledges and are interested in whether changes in one of these variables predicts changes in the other variables over the period. Importantly, individual comments can only be made after a pledge has been made; individual Facebook shares are elicited after a contribution is made, but can also take place without a monetary contribution. So on the individual level, comments must always succeed pledges. Yet, in the aggregate, comments and shares on an individual basis may increase the pledges made by other individuals subsequently. This is the individual and collective signaling effect we are after. That being said, we would posit that both comments and shares made by early backers within a project may attract new investors. Hence, the comments and shares may signal campaign characteristics to subsequent backers. The community interaction therefore is thought to be beneficial for campaign success. We discuss these results in the results section and tabulate the findings in the Appendix.

\section{Moderator Variable}

Our theoretical analysis implies that the signaling effect may vary depending on the perceived quality of the underlying campaign. Noteworthy, this could translate into potential backers evaluating either the characteristics of the campaign founder, the campaign itself, or the appeal of the campaign. We therefore proxy these characteristics using three dimensions to also provide robust and prudent estimates.

Novelty of solution: The novelty of the solution is operationalized using Im and Workman (2004) as to whether or not the solution is "out of the ordinary, revolutionary, stimulating, radical or unconventional". Again, upper and lower boundaries are derived from a seven-point Likert-type scale, with 7 = "strongly agree" and 1 = "strongly disagree". Cronbach's alpha is 0.90 .

Founder Skills - Trend Leadership: To proxy similarity based on innovative skills, we measure how technologically advanced the campaign founder appears following Franke, von Hippel,

\footnotetext{
${ }^{14}$ We collected all comments made on the corresponding Kickstarter page. As such, there is a theoretical possibility that creator responses are also included in the comments. Yet, this somehow only proxies for more vivid discussions as a creator would not comment alone (let alone comment frequently) but rather his unsolicited "comments" are generally reflected as updates on the main page. We therefore believe that our measure of comments proxies the signals provided by the community rather than active creator engagement.
} 
and Schreier (2006). We specially ask the question "The creator has ideas that are "ahead of the trend" to the raters. Upper and lower boundaries are derived from a seven-point Likert-type scale, with 7 = "strongly agree" and 1 = "strongly disagree". Evaluations showed an intraclass correlation coefficient for the innovativeness measure of 0.92 to 0.96 .

Video Quality: The overall appeal of the campaign is proxied by the visual representation in the campaign video. Especially, the role of the video in assessing campaign quality has been pointed out prior work (Mollick, 2014). We ask specifically, whether the video "is believable, has a high image quality, is visually interesting, is memorable, is original." upper and lower boundaries are derived from a seven-point Likert-type scale, with $7=$ "strongly agree" and $1=$ “strongly disagree". Cronbach's alpha is 0.89 .

\section{Control Variables}

We include several control variables into the cross-sectional model to control for specific product and campaign creator (team member) characteristics. Firstly, we control for team size, measuring the number of creators mentioned on the campaign page. In addition, we include the average age of the team (categories $1-5: 1=<20 ; 2=20-30 ; 3=30-40 ; 4=40-50 ; 5=>50$ ). We also specifically control for whether or not the campaign creators are female or whether a female is a member of the team. The dummy variable that takes on the value of one if the campaign creator is female and if a female is mentioned explicitly in the campaign page as a team member. This follows Fairlie and Robb (2007) and Greenberg and Mollick (2016) who advocate that females are at a disadvantage in accessing new venture financing. Following work on the role of human capital on entrepreneurial success (Davidsson and Honig, 2003), we include measures that capture the creators' completion of a higher education $(1=$ college educated, zero otherwise), a measure of technological skills (Likert scale 1-7; the creators possess execution, creative or technical skills (Cronbach's alpha=0.85)), and business skills (Likert scale 1-7; the creators possess social competence, risk-awareness, and financial know-how (Cronbach's alpha=0.80)). Following Voss et al. (2003) and Stock, Oliveira, and von Hippel (2014) we proxy product characteristics using two scales for hedonic product value (Likert scale 1-7; Affirmative answer whether the product is fun, exciting, enjoyable, or pleasant: Cronbach's alpha $=0.86$; higher values in the average denotes more hedonic product characteristic) and utilitarian product characteristics (Likert scale 1-7; Affirmative answer whether the product is necessary, practical, or solved a problem: Cronbach's alpha $=0.82$ : higher values in the average denotes more utilitarian product characteristic)). 


\section{$4 \quad$ Results}

We organize our results in eight tables. Table 1 presents the summary statistics, table $2 \mathrm{a}$ to $2 \mathrm{c}$ report the results for the cross-sectional analysis of the campaign success probabilities and the amount pledged to each campaign using the campaign quality sub-segments. Table 3-6 provide descriptive statistics and results from the stationarity, Granger causality, and cointegration analysis.

As to the summary statistics, table 1 reports that we have 572 project observations for which we have no missing values in the regressions. We can observe that some 47 percent of the campaigns successfully reach their campaign goal and on average collect some 50 thousand USD. As to the explanatory variables, the mean trend leadership score is 3.59 , while the quality of the campaign appearance is rated as 4.02 and the novelty of the solution exhibits moderate levels of innovativeness at 3.11.

Two out of three campaigns report more than one campaigner. About every third venture involves a female campaigner. The average age is somewhere in the 20-30 category. About every fourth venture reports a college degree on their campaign page. As it concerns the skills set of the campaigners, higher business skills (3.73) are slightly more prevalent than technical skills (3.61). Lastly, campaigns may comprise both hedonic and utilitarian products (3.83 vs. 4.55 , respectively).

[Insert table 1 about here]

\section{Cross-Sectional Regression Analysis - Success Probability}

Firstly, we find that an increase in the number of comments is associated with an increase of the log-odds of reaching the campaign goal $(\beta=2.961, \mathrm{p}<0.01)$, the effect for the Facebook shares is smaller but also statistically significant $(\beta=1.103, \mathrm{p}<0.1)$. Both effects are in line with hypothesis 1 and 2 . Among the control variables, having a female in the team increases the logodds of reaching the campaign goal $(\beta=1.609, \mathrm{p}<0.1)$, while the average age of the campaign team decreases the log-odds of doing so $(\beta=0.799, \mathrm{p}<0.01)$.

As it concerns the hypothesized differential effects of signal intensity, we can infer that the number of comments exhibits a much stronger effect on the likelihood to reach the campaign goal successfully. To further allude to this point more dynamically, we relegate to the subsequent Granger analysis. 
As it concerns the hypothesized diminishing effects of signals on campaign success table 2a reports that along the trend leadership dimensions, the coefficient for the number of comments provide remains statistically significant in all regressions estimated, but the coefficient declines from $\beta=4.955$ to $\beta=3.022$, for low and high levels of trend leadership respectively. Flow levels of the trend leadership component Facebook shares exhibit a statistically significant positive effect on the likelihood to reach the campaign goal $(\beta=1.428, p<0.05)$. However, the coefficient for the Facebook shares is insignificant in both the medium as well as the high trend leadership tertile.

Subsequently, we also tested whether the effect for both types of signals is affected differently if we split the sample according to campaign or product features. We can observe in table $2 b$ that the effect for the number of comments ranges from $\beta=4.043$ for the lowest tertiles of the novelty of the solution offered to $\beta=2.768$ for the highest tertiles. This corroborates the previously found positive but diminishing effect. Similar effects are reported in table $2 \mathrm{c}$, were we split the sample according to the perceived quality of campaign appearance (based on the impressions of the campaign video). Again, the coefficient for the number of comments is highly statistically significant in all models, but declines from $\beta=3.513$ for the lowest tertile to $\beta=2.887$ for the highest tertile. At the same time, all three regression models report that Facebook shares only act as signals for low levels of the trend leadership, novelty of the solution, and campaign appearance tertiles. With an increase in perceived campaign quality the signaling effect of social media support vanishes.

[Insert table 2a-c about here]

\section{Granger Causality}

Table 3 reports the descriptive statistics for the time series used for the Granger causality analysis. We focus in here on 104 projects that successfully reached their campaign goal. All in all, analyses are based on 3,016 daily observations $(\mathrm{T}=29)$. The projects are segmented into low/medium/high scores of the trend leadership rating, resulting in 22, 22, and 60 projects for each category. We only concentrate on the trend leadership variable, as the main effects derived in the previous analysis were similar for all three variables used for the sample split.

[Insert table 3 about here] 
We find that the amount pledged differs between the segments, such that the low ahead of trend segment and the medium ahead of trend segment receive substantially less capital, ranging from 5,000 to some 40,000 USD, while the high ahead of trend segment receives between some 90,000 up 600,000 USD. In addition, the number of comments and the Facebook shares per project varies considerably between the segments, with the high ahead of trend segment receiving substantially more comments and Facebook shares per project. To allow for meaningful comparisons, we aggregate all information for projects within each segment and log-transform the values to reduce the influence of outliers. Our time series then involves all projects within each segment over a 29-day time window (as noted above, we removed the last campaign day due to structural breaks in the comments time series). These data are the input for the Granger causality model to infer in which direction (if at all) comments and pledges are related to each other. All in all, all categories report a sufficiently high level of variation to allow for causal inferences using Granger analyses.

In addition to the results provided above, we are also interested in inferring causal inferences from our estimates. Firstly, considering a 5\% significance level, we find our time series to be integrated of first (I(1)) or second order (I(2)), as evidenced by confirmatory results of the ADF, KPSS and PP test in table $4 .^{15}$

[Insert table 4 about here]

Our results lack convincing evidence to decisively reject the possibility of no unit root at level. In consequence, we therefore adjusted the Toda-Yamamoto analysis, as outlined in section 3.2. In table 5 we report the $\chi^{2}$-test statistics and p-values obtained from the Granger causality MWald tests (against the null hypothesis of no Granger causality). We report our results for a time series containing a common 29-day interval for projects that have successfully reached their campaign goal. ${ }^{16}$

As it relates to our hypothesis 1 and 2 we find evidence for causality running from the number of comments to the amount pledged $\left(\chi^{2}=3.870, p=0.049\right)$ and but not for the number of Facebook shares. This supports the notion brought forward in hypothesis 2, but does not provide evidence for a causal effect between the number of Facebook shares and the amount pledged to

\footnotetext{
${ }^{15}$ Most of the series are difference stationary, i.e. I(1), when we apply the ADF, PP and KPSS tests, allowing for a drift and trend in each series. However, the variables pledged, pledged_high are found to be I(2) when considering a conclusive result of all three test approaches.

${ }^{16}$ Evidently, those that did not receive any comments and very little money pledged, show high correlations but cannot help to make inferences as variance in both, independent and dependent variables are missing. Other projects have varying days of the campaign, which may results comparing projects with unequal project length. This includes projects with 45 or 60 days, or even months with 30 days. We therefore opted to compare one common time frame. Hence, projects reported here all have a campaign length of 30 days.
} 
a campaign. Hence, there is some evidence from the cross-sectional analysis in favor of hypothesis 1 , but there is not enough evidence to decisively infer causality from Facebook shares to the amount pledged to the campaign. Yet, the effect of comments on the amount pledged is strong and robust, providing evidence for hypotheses 2.

As concerns the low ahead of trend segment, we find evidence for causality running from the number of comments to the amount pledged $\left(\chi^{2}=6.740, p=0.034\right)$. Similarly, for the medium level of ahead of trend, we find an even stronger Granger causality running from comments to the amount pledged $\left(\chi^{2}=4.140, \mathrm{p}=0.042\right)$. Lastly, there is no causality for the high ahead of trend segment. These results support the cross-sectional evidence provided earlier and document a causality between the aggregated signal "comments" on the amount pledged. At the contrary, we find that for Facebook shares, that the cross-sectional causality reported earlier may stem from reverse causality issues. We find that for the high ahead of trend segment, the causality runs from the amount pledged to the Facebook shares $\left(\chi^{2}=27.400, p=0.001\right)$.

We therefore corroborate that the positive effect of the signal depends on the quality of the campaign, such that the value of the signal erodes and becomes erroneous for very high levels of perceived quality. This provides evidence for both, the signaling effect of the comments that are publicly available for subsequent backers and the notion that with other quality information present, the crowd signal erodes in value. We therefore find evidence in favor of hypothesis 2 and 3. As with cross-sectional analysis, we find causality for the low and medium levels of the ahead of trend score. As such, we conclude that the effect reported previously is not only correlative but Granger-causal in nature.

[Insert table 5 about here]

All results in the MWALD Granger causality analysis in the sense of Toda and Yamamoto (1995) correspond with the results for bivariate cointegration (table 6).

[Insert table 6 about here]

Overall, we find evidence for our hypothesis, such that there is a direct effect of the numbers of publicly available campaign comments on both the probability to successfully reach the campaign goal, and on the number of pledges received. Yet, we do not find convincing evidence that the number of Facebook shares (of the link to the campaign webpage) presents a similarly relevant signal for potential backers to reduce information asymmetry. Even more so, we find 
that the causality between social media signals and the amount pledged runs in the opposite direction, such that more innovative and successful projects garner more social media attention. In addition, we find that the direct effect of the number of comments received on the amount pledged to the campaign is highest for the low and medium ahead of trend segment. Also, we find an almost negligible coefficient for comments on pledges in the high ahead of trend segment. These cross-sectional effects are corroborated by our Granger analyses. While we find causality in the low and medium segments of the ahead of trend variable, there is no unidirectional causality from comments to pledges in the high ahead of trend segment.

\section{$5 \quad$ Limitations and Extensions}

As with all research, this study is not without limitations. Firstly, we report that the performance effect of electronic word of mouth is conditional on the innovativeness of the campaign founders. We therefore also acknowledge that innovativeness is based on available campaign information. It may therefore be subjective. Hence, if behavior of campaign founders is mimetic and founders only claim to be innovative, when in fact the product is not, we may have false-positives; individuals only pretending innovative behavior. It may therefore be important to further study the product features of the underlying campaigns, especially based on information about the actual product delivered to test how comments before and after the campaign are reflective of underlying product innovativeness. One further conjecture from our analysis would be, that those that claim to be highly innovative may find it more difficult to live up to their promise of bringing a highly innovative product to market, especially as they gain less from crowd interactions. Time to market should therefore be longer. A possible extension could therefore especially involve an analysis of disgruntled customers reacting to possible over-statement of product characteristics.

Our models allows for negative feedback through comments. It might be worthwhile to explore the sentiment in comments generated further, to delineate whether entrepreneurs should only leverage the upside of social media channels or whether they need to pay attention to disgruntled voices raised here as well. Given the diminishing returns of positive electronic word of mouth through user generated content, it may well be that mitigating downsides might become more important (Fischer and Reuber, 2011).

Similarly, it might be important to extend our work along the lines of the underlying technology. Our work focusses on high technology products on Kickstarter. Effects might be different for less novel sets of technology, or in areas where ideas are very far from market inception and 
without any prototypes to show. In these instances, the sourcing part of crowdfunding might be more important than the mere capital contribution. Here, social media communication might be even more beneficial than in our setting. We may also find that mass personal communication might be more important when the underlying technology is very distant from commercialization. Hence, allowing for more heterogeneity when it comes to the underlying product and technology might provide additional insights. ${ }^{17}$ This may also involve theoretical models in which founder characteristics directly affect the choice of technology they want to product. An extension would involve breaking up the innovation measures along the lines of radical, incremental, or disruptive technologies and measuring these to provide an empirical test.

Noteworthy, we found that in the high ahead trend segment, the causality runs from the amount pledged to Facebook shares, implying a reverse causality. We believe this to be a finding that deserves further attention. It may well be that prior involvement by the crowd may strengthen personal opinions about a product and hence, may induce the sharing of information of social media. Prior work along these lines has found evidence that social media interactions and especially reciprocity fosters personal well-being (Zell and Moeller, 2017). As such, there may be mediating factors on the personal level that cause this reverse causality. We therefore believe this to be an important area for future research.

\section{Conclusion}

The literature on entrepreneurship has seen a surge in work pointing out the benefits that social media platforms may have for new product development and the successful engagement of external social capital (Fischer and Reuber, 2011, 2014). Work by Colombo, Franzoni, and Rossi-Lamastra (2015) shows that campaign founders can leverage their external social capital that resides within the crowdfunding community. They feature prominently, that crowdfunding platforms "[...] are not only intermediaries of monetary transactions, but also loci of social connections." (Colombo et al., 2015: 76).

Because individuals tend to approach problems with different innate approaches, we analyse whether crowdfunding campaign creators will benefit differentially when engaging in online communications and social media interactions in the process of financing and developing new innovative products. In our work, we formally model the impact of electronic word of mouth on outcomes depending on individual campaign quality. The model implies that the efficiency

\footnotetext{
${ }^{17}$ We thank an anonymous reviewer for extensive discussions on the heterogeneity of technology and the role of crowdsourcing rather than crowdfunding when product risk increases.
} 
of electronic word of mouth, informational resources provided through online interactions, is determined by the quality of the underlying campaign. Our work highlights the salient differences between mass personal communication such as Facebook and user generated content word of mouth. Facebook lacks the heftiness and persistence that user generated narratives, such as comments and reciprocal communications, may have. These insights should be critical for entrepreneurs in general, and crowdfunding campaigners, in particular.

In addition, we document that some campaigns are more likely than others to benefit from user generated communication and interaction. While a high quality campaign is benefitting from electronic word of mouth, the returns are diminishing. This is contrary to conventional wisdom relying on the ubiquitous assumption that more communication through various channels is always better (Fischer and Reuber, 2014). Our work highlights the interactive contingency of social media engagement and the campaign creator. We therefore extend prior work on the contingencies affecting the value of individuals' social capital (Stam et al., 2014; Vissa and Chacar, 2009). Whereas related studies in the crowdfunding literature consider static data related to social networks (Mitra and Gilbert, 2014; Colombo, Franzoni and Rossi-Lamastra, 2015; Allison et al., 2015), comments, or updates (Courtney, Dutta and Li, 2017; Gangi and Daniele, 2017), our work provides a contribution towards a more dynamic understanding of causal inferences between social activities of backers and funding effects. Our findings complement previous work on the opportunity costs involved in networking activities (Semrau and Werner, 2012; Watson, 2007). This implies that to achieve the benefits of electronics word of mouth, entrepreneurs need to develop campaigns, products, and communication in tandem. Content of social media communication is important, but should not be overstressed. We believe that practitioners need to approach this area with a certain note of sensitivity to achieve the objective of successfully reaching their campaign goal. 


\section{References}

Agrawal, A., Catalini, C., \& Goldfarb, A. (2015). Crowdfunding: Geography, social networks, and the timing of investment decisions. Journal of Economics \& Management Strategy, 24(2), 253-274.

Akaike, H. (1969). Fitting autoregressive models for prediction. Annals of the Institute of Statistical Mathematics, 21(1), 243-247.

Allison, T. H., Davis, B. C., Short, J. C., \& Webb, J. W. (2015). Crowdfunding in a prosocial microlending environment: Examining the role of intrinsic versus extrinsic cues. Entrepreneurship Theory and Practice, 39(1), 53-73.

Althoff, T., \& Leskovec, J. (2015, May). Donor retention in online crowdfunding communities: A case study of donorschoose. org. In Proceedings of the 24th International Conference on World Wide Web (34-44). International World Wide Web Conferences Steering Committee.

Arthurs, J. D., Busenitz, L. W., Hoskisson, R. E., \& Johnson, R. A. (2009). Signaling and initial public offerings: The use and impact of the lockup period. Journal of Business Venturing, 24(4), 360-372.

Arthurs, J. D., Busenitz, L. W., Hoskisson, R. E., \& Johnson, R. A. (2009). Signaling and initial public offerings: The use and impact of the lockup period. Journal of Business Venturing, 24(4), 360-372.

Bergh, D. D., Connelly, B. L., Ketchen, D. J., \& Shannon, L. M. (2014). Signalling theory and equilibrium in strategic management research: An assessment and a research agenda. Journal of Management Studies, 51(8), 1334-1360.

Certo, S. T. (2003). Influencing initial public offering investors with prestige: Signaling with board structures. Academy of Management Review, 28(3), 432-446.

Certo, S. T., Covin, J. G., Daily, C. M., \& Dalton, D. R. (2001). Wealth and the effects of founder management among IPO-stage new ventures. Strategic Management Journal, 22(6-7), 641-658.

Chowdhury, A., \& Mavrotas, G. (2006). FDI and growth: What causes what?. The World Economy, 29(1), 9-19.

Colombo, M. G., Franzoni, C., \& Rossi-Lamastra, C. (2015). Internal social capital and the attraction of early contributions in crowdfunding. Entrepreneurship Theory and Practice, $39(1), 75-100$.

Connelly, B. L., Certo, S. T., Ireland, R. D., \& Reutzel, C. R. (2011). Signaling theory: A review and assessment. Journal of Management, 37(1), 39-67.

Courtney, C., Dutta, S., \& Li, Y. (2017). Resolving information asymmetry: Signaling, endorsement, and crowdfunding success. Entrepreneurship Theory and Practice, 41(2), 265-290.

Cumming, Douglas J., Lars Hornuf, Moein Karami, and Denis Schweizer. "Disentangling crowdfunding from fraudfunding." (2016). Available on SSRN (Accessed: 20th December 2017).

Das, T. K., \& Teng, B. S. (2001). Trust, control, and risk in strategic alliances: An integrated framework. Organization studies, 22(2), 251-283.

Davidsson, P., \& Honig, B. (2003). The role of social and human capital among nascent entrepreneurs. Journal of Business Venturing, 18(3), 301-331.

Dickey, D. A., \& Fuller, W. A. (1979). Distribution of the estimators for autoregressive time series with a unit root. Journal of the American Statistical Association, 74(366a), 427-431.

Dickey, D. A., \& Fuller, W. A. (1981). Likelihood ratio statistics for autoregressive time series with a unit root. Econometrica: Journal of the Econometric Society, 1057-1072.

Dolado, J. J., \& Lütkepohl, H. (1996). Making Wald tests work for cointegrated VAR systems. Econometric Reviews, 15(4), 369-386. 
Ewens, M., \& Rhodes-Kropf, M. (2015). Is a VC Partnership Greater than the Sum of its Partners?. The Journal of Finance, 70(3), 1081-1113.

Fairlie, R. W., \& Robb, A. (2007). Families, human capital, and small business: Evidence from the characteristics of business owners survey. ILR Review, 60(2), 225-245.

Fischer, E., \& Reuber, A. R. (2011). Social interaction via new social media:(How) can interactions on Twitter affect effectual thinking and behavior?. Journal of Business Venturing, 26(1), 1-18.

Fischer, E., \& Reuber, A. R. (2014). Online entrepreneurial communication: Mitigating uncertainty and increasing differentiation via Twitter. Journal of Business Venturing, 29(4), 565-583.

Franke, N., Von Hippel, E., \& Schreier, M. (2006). Finding commercially attractive user innovations: A test of lead-user theory. Journal of Product Innovation Management, 23(4), 301-315.

Gable, S. L., \& Reis, H. T. (2010). Good news! Capitalizing on positive events in an interpersonal context. Advances in Experimental Social Psychology, 42, 195-257.

Gangi, F., \& Daniele, L. M. (2017). Remarkable Funders: How Early-Late Backers and Mentors Affect Reward-Based Crowdfunding Campaigns. International Business Research, 10(11), 58.

Giles, D. E. (1997). Causality between the measured and underground economies in New Zealand. Applied Economics Letters, 4(1), 63-67.

Granger, C. W. (1969). Investigating causal relations by econometric models and crossspectral methods. Econometrica: Journal of the Econometric Society, 424-438.

Greenberg, J., \& Mollick, E. (2016). Activist Choice Homophily and the Crowdfunding of Female Founders. Administrative Science Quarterly, 62(2), 341-374.

Hamilton, J. D. (1994). Time series analysis (Vol. 2). Princeton: Princeton University Press.

Hoetker, G. (2007). The use of logit and probit models in strategic management research: Critical issues. Strategic Management Journal, 28(4), 331-343.

Hussain, S., Guangju, W., Jafar, R. M. S., Ilyas, Z., Mustafa, G., \& Jianzhou, Y. (2017). Consumers' online information adoption behavior: Motives and antecedents of electronic word of mouth communications. Computers in Human Behavior.

Im, S., \& Workman Jr, J. P. (2004). Market orientation, creativity, and new product performance in high-technology firms. Journal of Marketing, 68(2), 114-132.

Janney, J. J., \& Folta, T. B. (2003). Signaling through private equity placements and its impact on the valuation of biotechnology firms. Journal of Business Venturing, 18(3), 361380 .

Johansen, S. (1988). Statistical analysis of cointegration vectors. Journal of Economic Dynamics and Control, 12(2), 231-254.

Johansen, S., \& Juselius, K. (1990). Maximum likelihood estimation and inference on cointegration with applications to the demand for money. Oxford Bulletin of Economics and Statistics, 52(2), 169-210

Kerr, W. R., Lerner, J., \& Schoar, A. (2011). The consequences of entrepreneurial finance: Evidence from angel financings. The Review of Financial Studies, 27(1), 20-55.

Kuppuswamy, V., \& Bayus, B. L. (2017). Does my contribution to your crowdfunding project matter?. Journal of Business Venturing, 32(1), 72-89.

Kurozumi, E., \& Yamamoto, T. (2000). Modified lag augmented vector autoregressions. Econometric Reviews, 19(2), 207-231.

Kwiatkowski, D., Phillips, P. C., Schmidt, P., \& Shin, Y. (1992). Testing the null hypothesis of stationarity against the alternative of a unit root: How sure are we that economic time series have a unit root? Journal of Econometrics, 54(1), 159-178.

Lee, J., \& Lio, Y. L. (1999). A note on Bayesian estimation and prediction for the betabinomial model. Journal of Statistical Computation and Simulation, 63(1), 73-91. 
Ljung, G. M., \& Box, G. E. (1978). On a measure of lack of fit in time series models. Biometrika, 65(2), 297-303.

Lukas, C. (2007). Managerial Expertise, Learning Potential, and Dynamic Incentives: Get More for Less? Managerial and Decision Economics, 28 (3): 195-211.

MacKinnon, J. G. (1991). Critical Values for Cointegration Tests. In: Long-Run Economic Relationships: Readings in Cointegration, eds. Engle, R. F., \& Granger, C. W. Oxford: Oxford University Press.

Massy, W., Montgomery, D. \& Morrison, D. (1970). Stochastic models of buying behavior. MIT Press.

Mavrotas, G., \& Kelly, R. (2001). Old wine in new bottles: Testing causality between savings and growth. The Manchester School, 69(s1), 97-105.

Mitra, T., \& Gilbert, E. (2014, February). The language that gets people to give: Phrases that predict success on kickstarter. In Proceedings of the 17th ACM conference on Computer supported cooperative work \& social computing (pp. 49-61). ACM.

Mollick, E. R. (2014). The dynamics of crowdfunding: An exploratory study. Journal of Business Venturing 29(1), 1-16.

Mollick, E. R., \& Kuppuswamy, V. (2014). After the campaign: Outcomes of crowdfunding. Available on SSRN (Accessed: 20th December 2017).

Mollick, E. R., \& Nanda, R. (2015). Wisdom or madness? Comparing crowds with expert evaluation in funding the arts. Management Science, 62(6), 1533-1553.

O’Sullivan, P. B., \& Carr, C. T. (2017). Masspersonal communication: A model bridging the mass-interpersonal divide. New Media \& Society, 1461444816686104.

Osterwald-Lenum, M. (1992). A note with quantiles of the asymptotic distribution of the maximum likelihood cointegration rank test statistics. Oxford Bulletin of Economics and Statistics, 54(3), 461-472.

Pearson, E.S. (1925). Bayes' Theorem, Examined in the Light of Experimental Sampling, Biometrika,

Vol. 17, No. 3/4: 388-442.

Phillips, P. C., \& Perron, P. (1988). Testing for a unit root in time series regression. Biometrika, 75(2), 335-346.

Pierce, J. R., \& Aguinis, H. (2013). The too-much-of-a-good-thing effect in management. Journal of Management, 39(2), 313-338.

Plummer, L. A., Allison, T. H., \& Connelly, B. L. (2016). Better together? Signaling interactions in new venture pursuit of initial external capital. Academy of Management Journal, 59(5), 1585-1604.

Prahalad, C. K., \& Ramaswamy, V. (2000). Co-opting customer competence. Harvard Business Review, 78(1), 79-90.

Rains, S. A., \& Keating, D. M. (2011). The social dimension of blogging about health: Health blogging, social support, and well-being. Communication Monographs, 78(4), 511-534

Rozzell, B., Piercy, C.W., Carr, C.T., King, S., Lane, B.L., Tornes, M., Johnson, A.J. and Wright, K.B., 2014. Notification pending: Online social support from close and nonclose relational ties via Facebook. Computers in Human Behavior, 38, pp.272-280.

Schwert, G. W. (1989). Tests for unit roots: A Monte Carlo investigation. Journal of Business \& Economic Statistics, 20(1), 5-17.

Semrau, T., \& Werner, A. (2012). The Two Sides of the Story: Network Investments and New Venture Creation. Journal of Small Business Management, 50(1), 159-180.

Shukur, G., \& Mantalos, P. (2000). A simple investigation of the Granger-causality test in integrated-cointegrated VAR systems. Journal of Applied Statistics, 27(8), 1021-1031.

Sims, C. A. (1972). Money, income, and causality. The American Economic Review, 62(4), $540-552$. 
Skellam, J.G. (1948). A Probability Distribution Derived from the Binomial Distribution by Regarding the Probability of Success as Variable Between the Sets of Trials. Journal of the Royal Statistical Society. Series B (Methodological), Vol. 10, No. 2: 257-261.

Spence, M. (1973). Job market signaling. The Quarterly Journal of Economics, 87(3), 355374.

Stam, W., Arzlanian, S., \& Elfring, T. (2014). Social Capital of Entrepreneurs and Small Firm Performance: A Meta-Analysis of Contextual and Methodological Moderators. Journal of Business Venturing, 29(1): 152-173.

Stock, R. M., Oliveira, P., \& Hippel, E. (2015). Impacts of Hedonic and Utilitarian User Motives on the Innovativeness of User-Developed Solutions. Journal of Product Innovation Management, 32(3), 389-403.

Toda, H. Y., \& Yamamoto, T. (1995). Statistical inference in vector autoregressions with possibly integrated processes. Journal of Econometrics, 66(1), 225-250.

Vissa, B., \& Chacar, A. S. (2009). Leveraging ties: the contingent value of entrepreneurial teams' external advice networks on Indian software venture performance. Strategic Management Journal, 30(11), 1179-1191.

Voss, K. E., Spangenberg, E. R., \& Grohmann, B. (2003). Measuring the hedonic and utilitarian dimensions of consumer attitude. Journal of marketing research, 40(3), 310-320

Walther, J. B., \& Boyd, S. (2002). Attraction to computer-mediated social support. Communication technology and society: Audience Adoption and Uses, 153188.

Watson, J. (2007). Modeling the relationship between networking and firm performance. Journal of Business Venturing, 22(6), 852-874

Zapata, H. O., \& Rambaldi, A. N. (1997). Monte Carlo evidence on cointegration and causation. Oxford Bulletin of Economics and Statistics, 59(2), 285-298.

Zell, A. L., \& Moeller, L. (2018). Are you happy for m e... on Facebook? The potential importance of "likes" and comments. Computers in Human Behavior, 78, 26-33. 


\section{Appendix}

Table 1: Summary Statistics $(\mathrm{n}=572)$

\begin{tabular}{|c|c|c|c|c|c|c|c|c|c|c|c|c|c|c|c|c|c|c|c|}
\hline & Variable & Mean & SD & Median & Max & 1 & 2 & 3 & 4 & 5 & 6 & 7 & 8 & 9 & 10 & 11 & 12 & 13 & 14 \\
\hline 1 & Campaign Success & 0.47 & 0.50 & 0.00 & 1.00 & & & & & & & & & & & & & & \\
\hline 2 & Amount Pledged & 52,819 & 164,286 & 5,366 & $1,354,793$ & 0.30 & & & & & & & & & & & & & \\
\hline 3 & No. of Comments & 42.51 & 108.63 & 5.00 & $1,274.00$ & 0.34 & 0.64 & & & & & & & & & & & & \\
\hline 4 & No. Of Facebook Shares & 1,038 & 2,405 & 277 & 16,372 & 0.31 & 0.65 & 0.50 & & & & & & & & & & & \\
\hline 5 & Trend Leadership & 3.59 & 1.69 & 4.00 & 7.00 & 0.15 & 0.18 & 0.12 & 0.19 & & & & & & & & & & \\
\hline 6 & Quality of Appearance & 4.02 & 1.56 & 4.00 & 7.00 & 0.25 & 0.22 & 0.24 & 0.25 & 0.41 & & & & & & & & & \\
\hline 7 & Novelty of Solution & 3.11 & 1.44 & 3.00 & 7.00 & 0.14 & 0.14 & 0.13 & 0.21 & 0.70 & 0.52 & & & & & & & & \\
\hline 8 & Teamsize & 1.74 & 1.05 & 1.00 & 4.00 & 0.19 & 0.18 & 0.23 & 0.20 & 0.10 & 0.21 & 0.13 & & & & & & & \\
\hline 9 & Female Founder/Team-Member & 0.30 & 0.46 & 0.00 & 1.00 & 0.05 & -0.08 & -0.09 & 0.02 & -0.03 & 0.03 & 0.00 & 0.24 & & & & & & \\
\hline 10 & Age & 2.12 & 0.96 & 2.00 & 4.00 & -0.17 & -0.03 & -0.06 & -0.06 & -0.08 & -0.14 & -0.08 & -0.12 & -0.10 & & & & & \\
\hline 11 & Higher Education & 0.27 & 0.44 & 0.00 & 1.00 & 0.01 & -0.06 & 0.00 & -0.01 & 0.06 & 0.05 & 0.05 & 0.01 & 0.00 & -0.02 & & & & \\
\hline 12 & Technological Skills & 3.61 & 1.51 & 3.67 & 7.00 & -0.03 & -0.03 & -0.07 & -0.01 & -0.20 & -0.23 & -0.17 & -0.02 & -0.02 & 0.08 & 0.03 & & & \\
\hline 13 & Business Skills & 3.73 & 1.24 & 3.67 & 7.00 & -0.01 & -0.05 & -0.04 & -0.02 & -0.19 & -0.20 & -0.16 & 0.01 & 0.01 & 0.06 & 0.03 & 0.70 & & \\
\hline 14 & Hedonic Product Value & 3.83 & 1.81 & 4.00 & 7.00 & 0.17 & 0.15 & 0.14 & 0.11 & 0.19 & 0.25 & 0.23 & 0.04 & 0.01 & -0.12 & -0.02 & -0.06 & -0.08 & \\
\hline 15 & Utilitarian Product Value & 4.55 & 1.54 & 5.00 & 7.00 & -0.01 & 0.02 & 0.01 & 0.05 & 0.32 & 0.25 & 0.44 & 0.01 & 0.02 & 0.14 & -0.04 & -0.12 & -0.14 & -0.11 \\
\hline
\end{tabular}


Table 2a: Logit Regression - Dep. Variable Reaching Campaign Goal

\begin{tabular}{|c|c|c|c|c|}
\hline & $\begin{array}{l}\text { (1) } \\
\text { Main }\end{array}$ & $\begin{array}{c}(2) \\
\text { Trend } \\
\text { Leadership - } \\
\text { Low }\end{array}$ & $\begin{array}{c}\text { (3) } \\
\text { Trend } \\
\text { Leadership - } \\
\text { Medium }\end{array}$ & $\begin{array}{c}(4) \\
\text { Trend } \\
\text { Leadership - } \\
\text { High } \\
\end{array}$ \\
\hline No. of Comments & $\begin{array}{c}2.961^{* * *} \\
(0.000)\end{array}$ & $\begin{array}{c}4.955^{* * *} * \\
(0.000)\end{array}$ & $\begin{array}{c}3.736^{* * *} \\
(0.000)\end{array}$ & $\begin{array}{c}3.022 * * * \\
(0.000)\end{array}$ \\
\hline Facebook Shares & $\begin{array}{l}1.103^{*} \\
(0.082)\end{array}$ & $\begin{array}{l}1.428^{* *} \\
(0.017)\end{array}$ & $\begin{array}{c}1.187 \\
(0.108)\end{array}$ & $\begin{array}{c}1.002 \\
(0.986)\end{array}$ \\
\hline Trend Leadership & $\begin{array}{c}1.007 \\
(0.943)\end{array}$ & $\begin{array}{c}0.291 * * \\
(0.044)\end{array}$ & $\begin{array}{c}0.551 \\
(0.178)\end{array}$ & $\begin{array}{c}2.629 * * * \\
(0.007)\end{array}$ \\
\hline Quality of Campaign Appearance & $\begin{array}{c}0.930 \\
(0.443)\end{array}$ & $\begin{array}{c}0.966 \\
(0.861)\end{array}$ & $\begin{array}{c}0.799 \\
(0.192)\end{array}$ & $\begin{array}{c}0.902 \\
(0.556)\end{array}$ \\
\hline Novelty of the Solution & $\begin{array}{c}1.084 \\
(0.541)\end{array}$ & $\begin{array}{c}1.171 \\
(0.675)\end{array}$ & $\begin{array}{l}1.744^{* * *} \\
(0.032)\end{array}$ & $\begin{array}{c}0.806 \\
(0.277)\end{array}$ \\
\hline Teamsize & $\begin{array}{c}0.886 \\
(0.315)\end{array}$ & $\begin{array}{c}0.643 \\
(0.112)\end{array}$ & $\begin{array}{l}0.666^{*} \\
(0.095)\end{array}$ & $\begin{array}{l}1.404^{*} \\
(0.084)\end{array}$ \\
\hline Female Founder/Team-Member & $\begin{array}{l}1.609^{*} \\
(0.061)\end{array}$ & $\begin{array}{c}2.969^{* *} \\
(0.048)\end{array}$ & $\begin{array}{c}1.520 \\
(0.370)\end{array}$ & $\begin{array}{l}1.469 \\
(0.401)\end{array}$ \\
\hline Age & $\begin{array}{l}0.799^{*} \\
(0.076)\end{array}$ & $\begin{array}{c}0.861 \\
(0.581)\end{array}$ & $\begin{array}{c}0.843 \\
(0.480)\end{array}$ & $\begin{array}{c}0.687 \\
(0.113)\end{array}$ \\
\hline Higher Education & $\begin{array}{c}1.079 \\
(0.766)\end{array}$ & $\begin{array}{l}1.987 \\
(0.224)\end{array}$ & $\begin{array}{c}0.835 \\
(0.705)\end{array}$ & $\begin{array}{l}1.025 \\
(0.957)\end{array}$ \\
\hline Technological Skills & $\begin{array}{c}0.957 \\
(0.688)\end{array}$ & $\begin{array}{c}0.968 \\
(0.888)\end{array}$ & $\begin{array}{c}0.826 \\
(0.380)\end{array}$ & $\begin{array}{c}0.816 \\
(0.319)\end{array}$ \\
\hline Business Skills & $\begin{array}{c}1.192 \\
(0.197)\end{array}$ & $\begin{array}{c}0.991 \\
(0.971)\end{array}$ & $\begin{array}{l}1.486 \\
(0.143)\end{array}$ & $\begin{array}{l}1.575^{*} \\
(0.095)\end{array}$ \\
\hline Hedonic Product Value & $\begin{array}{l}1.018 \\
(0.800)\end{array}$ & $\begin{array}{c}0.707 * * \\
(0.037)\end{array}$ & $\begin{array}{l}1.336^{* *} \\
(0.031)\end{array}$ & $\begin{array}{c}0.931 \\
(0.584)\end{array}$ \\
\hline Utilitarian Product Value & $\begin{array}{c}0.987 \\
(0.884) \\
\end{array}$ & $\begin{array}{c}1.071 \\
(0.698) \\
\end{array}$ & $\begin{array}{c}1.165 \\
(0.386) \\
\end{array}$ & $\begin{array}{c}0.777 \\
(0.142) \\
\end{array}$ \\
\hline Chi-Square & 311.62 & 121.93 & 124.35 & 104.99 \\
\hline $\mathrm{P}>$ Chi-Square & 0.000 & 0.000 & 0.000 & 0.000 \\
\hline Observations & 572 & 178 & 204 & 190 \\
\hline
\end{tabular}


Table 2b: Logit Regression - Dep. Variable Reaching Campaign Goal

\begin{tabular}{|c|c|c|c|c|}
\hline & $\begin{array}{l}\text { (1) } \\
\text { Main }\end{array}$ & $\begin{array}{l}\text { (2) } \\
\text { Novelty of } \\
\text { Solution - } \\
\text { Low }\end{array}$ & $\begin{array}{l}\text { (3) } \\
\text { Novelty of } \\
\text { Solution - } \\
\text { Medium } \\
\end{array}$ & $\begin{array}{c}(4) \\
\text { Novelty of } \\
\text { Solution - } \\
\text { High } \\
\end{array}$ \\
\hline No. of Comments & $\begin{array}{c}2.961 * * * \\
(0.000)\end{array}$ & $\begin{array}{c}4.043^{* * *} \\
(0.000)\end{array}$ & $\begin{array}{c}3.744^{* * *} \\
(0.000)\end{array}$ & $\begin{array}{c}2.768 * * * \\
(0.000)\end{array}$ \\
\hline Facebook Shares & $\begin{array}{l}1.103^{*} \\
(0.082)\end{array}$ & $\begin{array}{l}1.388^{* *} \\
(0.040)\end{array}$ & $\begin{array}{c}1.048 \\
(0.600)\end{array}$ & $\begin{array}{l}1.085 \\
(0.418)\end{array}$ \\
\hline Trend Leadership & $\begin{array}{c}1.007 \\
(0.943)\end{array}$ & $\begin{array}{c}1.108 \\
(0.650)\end{array}$ & $\begin{array}{c}1.000 \\
(1.000)\end{array}$ & $\begin{array}{c}0.931 \\
(0.729)\end{array}$ \\
\hline Quality of Campaign Appearance & $\begin{array}{c}0.930 \\
(0.443)\end{array}$ & $\begin{array}{c}1.384 \\
(0.162)\end{array}$ & $\begin{array}{l}0.753^{*} \\
(0.057)\end{array}$ & $\begin{array}{c}0.798 \\
(0.247)\end{array}$ \\
\hline Novelty of the Solution & $\begin{array}{c}1.084 \\
(0.541)\end{array}$ & $\begin{array}{c}2.021 \\
(0.409)\end{array}$ & $\begin{array}{c}0.687 \\
(0.329)\end{array}$ & $\begin{array}{l}1.222 \\
(0.542)\end{array}$ \\
\hline Teamsize & $\begin{array}{c}0.886 \\
(0.315)\end{array}$ & $\begin{array}{l}1.018 \\
(0.953)\end{array}$ & $\begin{array}{l}0.680^{*} \\
(0.076)\end{array}$ & $\begin{array}{l}1.028 \\
(0.885)\end{array}$ \\
\hline Female Founder/Team-Member & $\begin{array}{l}1.609^{*} \\
(0.061)\end{array}$ & $\begin{array}{c}0.500 \\
(0.301)\end{array}$ & $\begin{array}{c}2.994 * * * \\
(0.007)\end{array}$ & $\begin{array}{l}1.918 \\
(0.171)\end{array}$ \\
\hline Age & $\begin{array}{l}0.799^{*} \\
(0.076)\end{array}$ & $\begin{array}{c}0.917 \\
(0.760)\end{array}$ & $\begin{array}{c}0.750 \\
(0.149)\end{array}$ & $\begin{array}{c}0.838 \\
(0.470)\end{array}$ \\
\hline Higher Education & $\begin{array}{c}1.079 \\
(0.766)\end{array}$ & $\begin{array}{l}0.320^{*} \\
(0.085)\end{array}$ & $\begin{array}{l}1.222 \\
(0.641)\end{array}$ & $\begin{array}{l}1.656 \\
(0.291)\end{array}$ \\
\hline Technological Skills & $\begin{array}{c}0.957 \\
(0.688)\end{array}$ & $\begin{array}{c}0.709 \\
(0.229)\end{array}$ & $\begin{array}{c}0.862 \\
(0.411)\end{array}$ & $\begin{array}{c}1.081 \\
(0.689)\end{array}$ \\
\hline Business Skills & $\begin{array}{l}1.192 \\
(0.197)\end{array}$ & $\begin{array}{c}1.482 \\
(0.200)\end{array}$ & $\begin{array}{l}1.309 \\
(0.250)\end{array}$ & $\begin{array}{l}1.025 \\
(0.920)\end{array}$ \\
\hline Hedonic Product Value & $\begin{array}{l}1.018 \\
(0.800)\end{array}$ & $\begin{array}{c}0.950 \\
(0.759)\end{array}$ & $\begin{array}{l}1.171 \\
(0.165)\end{array}$ & $\begin{array}{c}0.940 \\
(0.654)\end{array}$ \\
\hline Utilitarian Product Value & $\begin{array}{c}0.987 \\
(0.884) \\
\end{array}$ & $\begin{array}{l}0.642 * * \\
(0.024)\end{array}$ & $\begin{array}{l}1.200 \\
(0.209) \\
\end{array}$ & $\begin{array}{c}1.047 \\
(0.810) \\
\end{array}$ \\
\hline Chi-Square & 311.62 & 125.60 & 134.62 & 80.76 \\
\hline $\mathrm{P}>$ Chi-Square & 0.000 & 0.000 & 0.000 & 0.000 \\
\hline Observations & 572 & 161 & 244 & 167 \\
\hline
\end{tabular}


Table 2c: Logit Regression - Dep. Variable Reaching Campaign Goal

\begin{tabular}{|c|c|c|c|c|}
\hline & $\begin{array}{l}(1) \\
\text { Main }\end{array}$ & $\begin{array}{c}\text { (2) } \\
\text { Quality of } \\
\text { Appearance } \\
\text { - Low } \\
\end{array}$ & $\begin{array}{c}\text { (3) } \\
\text { Quality of } \\
\text { Appearance - } \\
\text { Medium }\end{array}$ & $\begin{array}{c}\text { (4) } \\
\text { Quality of } \\
\text { Appearance } \\
\text { - High } \\
\end{array}$ \\
\hline No. of Comments & $\begin{array}{c}2.961 * * * \\
(0.000)\end{array}$ & $\begin{array}{c}3.513^{* * *} \\
(0.000)\end{array}$ & $\begin{array}{c}3.280^{* * *} \\
(0.000)\end{array}$ & $\begin{array}{c}2.887 * * * \\
(0.000)\end{array}$ \\
\hline Facebook Shares & $\begin{array}{l}1.103^{*} \\
(0.082)\end{array}$ & $\begin{array}{c}1.300^{* * *} \\
(0.002)\end{array}$ & $\begin{array}{c}1.099 \\
(0.284)\end{array}$ & $\begin{array}{c}1.010 \\
(0.941)\end{array}$ \\
\hline Trend Leadership & $\begin{array}{l}1.007 \\
(0.943)\end{array}$ & $\begin{array}{c}0.851 \\
(0.280)\end{array}$ & $\begin{array}{l}1.033 \\
(0.844)\end{array}$ & $\begin{array}{l}1.063 \\
(0.767)\end{array}$ \\
\hline Quality of Campaign Appearance & $\begin{array}{c}0.930 \\
(0.443)\end{array}$ & $\begin{array}{c}0.980 \\
(0.927)\end{array}$ & $\begin{array}{c}0.831 \\
(0.531)\end{array}$ & $\begin{array}{c}1.763 \\
(0.256)\end{array}$ \\
\hline Novelty of the Solution & $\begin{array}{c}1.084 \\
(0.541)\end{array}$ & $\begin{array}{c}1.861^{* * *} \\
(0.006)\end{array}$ & $\begin{array}{c}1.029 \\
(0.895)\end{array}$ & $\begin{array}{c}0.742 \\
(0.208)\end{array}$ \\
\hline Teamsize & $\begin{array}{c}0.886 \\
(0.315)\end{array}$ & $\begin{array}{c}0.706 \\
(0.101)\end{array}$ & $\begin{array}{c}0.974 \\
(0.890)\end{array}$ & $\begin{array}{l}1.000 \\
(0.999)\end{array}$ \\
\hline Female Founder/Team-Member & $\begin{array}{l}1.609^{*} \\
(0.061)\end{array}$ & $\begin{array}{c}0.934 \\
(0.867)\end{array}$ & $\begin{array}{c}1.850 \\
(0.107)\end{array}$ & $\begin{array}{c}2.289 \\
(0.130)\end{array}$ \\
\hline Age & $\begin{array}{l}0.799^{*} \\
(0.076)\end{array}$ & $\begin{array}{c}1.139 \\
(0.481)\end{array}$ & $\begin{array}{c}0.666^{* *} \\
(0.045)\end{array}$ & $\begin{array}{c}0.510^{* *} \\
(0.023)\end{array}$ \\
\hline Higher Education & $\begin{array}{c}1.079 \\
(0.766)\end{array}$ & $\begin{array}{c}1.239 \\
(0.590)\end{array}$ & $\begin{array}{c}1.221 \\
(0.618)\end{array}$ & $\begin{array}{c}1.106 \\
(0.848)\end{array}$ \\
\hline Technological Skills & $\begin{array}{c}0.957 \\
(0.688)\end{array}$ & $\begin{array}{c}0.813 \\
(0.205)\end{array}$ & $\begin{array}{c}0.960 \\
(0.813)\end{array}$ & $\begin{array}{c}1.087 \\
(0.736)\end{array}$ \\
\hline Business Skills & $\begin{array}{c}1.192 \\
(0.197)\end{array}$ & $\begin{array}{l}1.300 \\
(0.166)\end{array}$ & $\begin{array}{c}1.322 \\
(0.249)\end{array}$ & $\begin{array}{c}0.909 \\
(0.755)\end{array}$ \\
\hline Hedonic Product Value & $\begin{array}{l}1.018 \\
(0.800)\end{array}$ & $\begin{array}{c}1.039 \\
(0.712)\end{array}$ & $\begin{array}{l}1.076 \\
(0.509)\end{array}$ & $\begin{array}{c}0.918 \\
(0.583)\end{array}$ \\
\hline Utilitarian Product Value & $\begin{array}{c}0.987 \\
(0.884) \\
\end{array}$ & $\begin{array}{l}0.776^{*} \\
(0.065)\end{array}$ & $\begin{array}{c}1.131 \\
(0.386) \\
\end{array}$ & $\begin{array}{c}1.087 \\
(0.667) \\
\end{array}$ \\
\hline Chi-Square & 311.62 & 169.38 & 152.31 & 68.09 \\
\hline $\mathrm{P}>$ Chi-Square & 0.000 & 0.000 & 0.000 & 0.000 \\
\hline Observations & 572 & 300 & 255 & 144 \\
\hline
\end{tabular}


Table 3: Descriptive Statistics of the Time Series used for Granger Causality Analysis

\begin{tabular}{lccrrr}
\hline Variable & T & Mean & St. Dev. & Min & Max \\
\hline All segments combined (N=104 projects, aggregate values) & & & \\
\hline pledged & 29 & $251,798.00$ & $133,038.00$ & $113,430.00$ & $709,117.00$ \\
fb_shares & 29 & $5,280.00$ & $4,196.00$ & $2,051.00$ & $22,035.00$ \\
comments & 29 & 145.00 & 75.60 & 70.00 & 450.00 \\
\hline Low,,ahead of trend“ segment (N=22 & projects, aggregate values) & & \\
\hline pledged_low & 29 & $19,603.00$ & $9,134.00$ & $9,442.00$ & $42,475.00$ \\
fb_shares_low & 29 & $1,025.00$ & 762.00 & 202.00 & $3,403,00$ \\
comments_low & 29 & 13.70 & 10.80 & 2.00 & 50.00 \\
\hline Medium,,ahead of trend“ segment $(N=22$ projects, aggregate values) & & \\
\hline pledged_medium & 29 & $14,720.00$ & $8,167.00$ & 5,588 & $41,780.00$ \\
fb_shares_medium & 29 & 438.00 & 478.00 & 87.00 & $2,339.00$ \\
comments_medium & 29 & 12.60 & 6.75 & 4.00 & 31.00 \\
\hline High ,ahead of trend“ segment $(N=60$ projects, aggregate values) & & \\
\hline pledged_high & 29 & $217,475.00$ & $122,124.00$ & $95,788.00$ & $634,520.00$ \\
fb_shares_high & 29 & $3,926.00$ & $3,213.00$ & $1,187.00$ & $16,293.00$ \\
comments_high & 29 & 119.00 & 62.10 & 50.00 & 369.00 \\
\hline
\end{tabular}

The table reports 3 the aggregate daily amount of comments, Facebook shares, and pledges for all projects cumulatively and for all projects within each trend segment. Projects that have common project duration of 30 days are included. The table reports absolute levels (in USD) 
Table 4: Unit Root - First differences

\begin{tabular}{|c|c|c|c|c|c|c|}
\hline & ADF_constant & ADF_trend & PP_const & $\mathrm{PP}$ trend & KPSS_const & KPSS_trend \\
\hline \multicolumn{7}{|c|}{ All segments combined } \\
\hline pledged & -2.34 & $-3.35(0.10)$ & $-4.18(0.01)$ & $-5.24(0.01)$ & $0.66(0.05)$ & 0.06 \\
\hline fb_shares & $-4.78(0.01)$ & $-5.04(0.01)$ & $-7.75(0.01)$ & $-8.37(0.01)$ & 0.29 & 0.06 \\
\hline comments & $-4.54(0.01)$ & $-4.80(0.01)$ & $-5.93(0.01)$ & $-6.52(0.01)$ & $0.37(0.10)$ & 0.05 \\
\hline \multicolumn{7}{|c|}{ Low ,, ahead of trend" segment } \\
\hline pledged_low & $-3.36(0.05)$ & $-3.44(0.10)$ & $-6.28(0.01)$ & $-6.48(0.01)$ & 0.16 & 0.05 \\
\hline fb_shares_low & $-5.21(0.01)$ & $-5.10(0.01)$ & $-8.33(0.01)$ & $-8.23(0.01)$ & 0.09 & 0.05 \\
\hline comments_low & $-4.88(0.01)$ & $-5.07(0.01)$ & $-7.78(0.01)$ & $-8.18(0.01)$ & 0.24 & 0.07 \\
\hline \multicolumn{7}{|c|}{ Medium ,, ahead of trend“ segment } \\
\hline pledged_medium & $-7.56(0.01)$ & $-9.06(0.01)$ & $-12.16(0.01)$ & $-15.17(0.01)$ & $0.44(0.10)$ & 0.09 \\
\hline fb_shares_medium & $-6.40(0.01)$ & $-7.07(0.01)$ & $-9.36(0.01)$ & $-10.64(0.01)$ & $0.37(0.10)$ & 0.08 \\
\hline comments_medium & $-3.93(0.01)$ & $-3.96(0.05)$ & $-6.49(0.01)$ & $-6.60(0.01)$ & 0.21 & 0.04 \\
\hline \multicolumn{7}{|c|}{ High ,, ahead of trend" segment } \\
\hline pledged_high & -2.28 & $-3.28(0.10)$ & $-5.12(0.01)$ & $-6.67(0.01)$ & $0.67(0.05)$ & 0.06 \\
\hline fb_shares_high & $-4.23(0.01)$ & $-4.38(0.01)$ & $-6.25(0.01)$ & $-6.54(0.01)$ & 0.27 & 0.06 \\
\hline comments_high & $-4.50(0.01)$ & $-4.69(0.01)$ & $-6.53(0.01)$ & $-7.11(0.01)$ & 0.32 & 0.05 \\
\hline
\end{tabular}

Results report the Augmented Dickey-Fuller (ADF), Phillips-Perron (PP) and Kwiatkowski-Phillips-Schmidt-Shin (KPSS) test results. Estimations with deterministic terms constant and trend. ADF H0: Series has a unit root, PP H0: Series has a unit root, KPSS H0: Series is stationary. ADF critical values drift $(1,5,10 \mathrm{pct}):-3.58-2.93-2.60$. ADF critical values drift+trend $(1,5,10 \mathrm{pct}):-4.15-3.50-3.18$. Critical values are taken from Hamilton (1994) and Dickey and Fuller (1981). PP critical values drift (1, 5, 10pct): -3.70 -2.97 -2.63. PP critical values drift+trend (1, 5, 10pct): -4.34 -3.59 -3.23. Critical values are taken from MacKinnon (1991). KPSS critical values drift (1, 5, 10pct): 0.350 .46 0.74. KPSS critical values drift+trend $(1,5,10 \mathrm{pct}): 0.120 .150 .22$. Critical values are taken from Based on Kwiatkowski et al. (1992). ADF optimum lag length is estimated with Bayesian/Schwartz information criteria (BIC). KPSS test maximum lag order (bandwidth) is chosen according to Schwert (1989). PP bandwidth is estimated with Newey-West standard errors using a Bartlett window. p-values in parentheses. 
Table 5: Toda and Yamamoto (1995) modified Wald (MWald) test for Granger causality

\begin{tabular}{|c|c|c|c|c|}
\hline Variables & $\mathrm{Lag} / \mathrm{m}_{\max }$ & $\chi^{2}$ & p-value & Conclusion \\
\hline \multicolumn{5}{|l|}{ All segments combined } \\
\hline fb_shares $\nrightarrow$ pledged & $1(2)$ & 0.531 & 0.466 & No causality \\
\hline pledged $\nrightarrow$ fb_shares & $1(2)$ & 0.636 & 0.429 & \\
\hline comments $\nrightarrow$ pledged & $1(2)$ & $3.870 * *$ & 0.049 & Unidirectional causality \\
\hline pledged $\nrightarrow$ comments & $1(2)$ & 2.690 & 0.101 & comments $\rightarrow$ pledged \\
\hline \multicolumn{5}{|l|}{ Low ,, ahead of trend“ segment } \\
\hline fb_shares_low $\nrightarrow$ pledged_low & $2(1)$ & 0.389 & 0.823 & No causality \\
\hline pledged_low $\nrightarrow$ fb_shares_low & $2(1)$ & 1.270 & 0.530 & \\
\hline comments_low $\nrightarrow$ pledged_low & $2(1)$ & $6.740 * *$ & 0.034 & Unidirectional causality \\
\hline pledged_low $\nrightarrow$ comments_low & $2(1)$ & 2.320 & 0.313 & comments_low $\rightarrow$ pledged_low \\
\hline \multicolumn{5}{|l|}{ Medium ,, ahead of trend" segment } \\
\hline fb_shares_medium $\nrightarrow$ pledged_medium & $2(1)$ & 4.380 & 0.112 & No causality \\
\hline pledged_medium $\nrightarrow$ fb_shares_medium & $2(1)$ & 4.340 & 0.114 & \\
\hline comments_medium $\nrightarrow$ pledged_medium & $1(1)$ & $4.140 * *$ & 0.042 & Unidirectional causality \\
\hline pledged_medium $\nrightarrow$ comments_medium & $1(1)$ & 0.010 & 0.920 & comments_medium $\rightarrow$ pledged_medium \\
\hline \multicolumn{5}{|l|}{ High ,, ahead of trend“ segment } \\
\hline fb_shares_high $\nrightarrow$ pledged_high & $4(2)$ & 3.050 & 0.550 & Unidirectional causality \\
\hline pledged_high $\nrightarrow$ fb_shares_high & $4(2)$ & $27.400 * * *$ & 0.001 & pledged_high $\rightarrow$ fb_shares_high \\
\hline comments_high $\nrightarrow$ pledged_high & $3(2)$ & 1.460 & 0.691 & No causality \\
\hline pledged_high $\nrightarrow$ comments_high & $3(2)$ & 4.300 & 0.231 & \\
\hline
\end{tabular}

$* * * \mathrm{p} \leq 0.01, * * \mathrm{p} \leq 0.05, * \mathrm{p} \leq 0.10$ significance level. $\chi^{2}$ and $\mathrm{p}$-values are MWald test results. $\nrightarrow$ denotes $\mathrm{H} 0=\mathrm{No}$ Granger-causality. Tested with deterministic terms 'constant and trend' at maxlag $=, T=29$. The Granger analysis employs log values of absolute values reported in table 3. Optimal lags are based on VAR estimations (AIC, BIC/SIC, FPE), Ljung-Box (1978) portmanteau test (asymptotic) for autocorrelation and inverse roots of AR characteristics of polynomials for dynamic stability. An autoregressive conditional heteroskedasticity $(\mathrm{ARCH})$ test was further considered to control for residual heteroscedasticity and a Jarque-Bera goodness-of-fit test to ensure dynamic stability of the model. Values in parentheses indicate the maximum order of integration. 
Table 6: Johansen and Juselius (1990) cointegration test

\begin{tabular}{|c|c|c|c|c|c|}
\hline & \multicolumn{2}{|c|}{ Rank Eigenvalue } & Trace Sig. & Max eigenval. Sig. & Lag \\
\hline \multicolumn{6}{|c|}{ All segments combined } \\
\hline pledged & $\mathrm{r} \leq 1$ & 0.209 & 6.340 & 6.340 & 2 \\
\hline fb_shares & $\mathrm{r}=0$ & 0.422 & 21.100 & 14.800 & 2 \\
\hline pledged & $\mathrm{r} \leq 1$ & 0.184 & 5.480 & 5.480 & 2 \\
\hline comments & $\mathrm{r}=0$ & 0.504 & $24.400 *$ & $18.900 *$ & 2 \\
\hline \multicolumn{6}{|c|}{ Low ,, ahead of trend" segment } \\
\hline pledged_low & $\mathrm{r} \leq 1$ & 0.278 & 8.800 & 8.800 & 2 \\
\hline fb_shares_low & $\mathrm{r}=0$ & 0.377 & 21.600 & 12.800 & 2 \\
\hline pledged_low & $\mathrm{r} \leq 1$ & 0.292 & 9.330 & 9.330 & 2 \\
\hline comments_low & $\mathrm{r}=0$ & 0.484 & $27.200 * *$ & $17.800 *$ & 2 \\
\hline \multicolumn{6}{|c|}{ Medium ,, ahead of trend“ segment } \\
\hline pledged_medium & $\mathrm{r} \leq 1$ & 0.242 & 7.490 & 7.490 & 2 \\
\hline fb_shares_medium & $\mathrm{r}=0$ & 0.395 & 21.100 & 13.600 & 2 \\
\hline pledged_medium & $\mathrm{r} \leq 1$ & 0.318 & 9.940 & 9.940 & 3 \\
\hline comments_medium & $\mathrm{r}=0$ & 0.551 & $30.800 * * *$ & $20.800 * *$ & 3 \\
\hline \multicolumn{6}{|c|}{ High ,, ahead of trend“ segment0 } \\
\hline pledged_high & $\mathrm{r} \leq 1$ & 0.279 & 7.860 & 7.860 & 5 \\
\hline fb_shares_high & $\mathrm{r}=0$ & 0.676 & $34.900 * * *$ & $27.000 * * *$ & 5 \\
\hline pledged_high & $\mathrm{r} \leq 1$ & 0.181 & 5.200 & 5.200 & 3 \\
\hline comments_high & $\mathrm{r}=0$ & 0.476 & 22.000 & 16.800 & 3 \\
\hline
\end{tabular}


Figure 1: Dynamic development of comments, Facebook shares and pledges
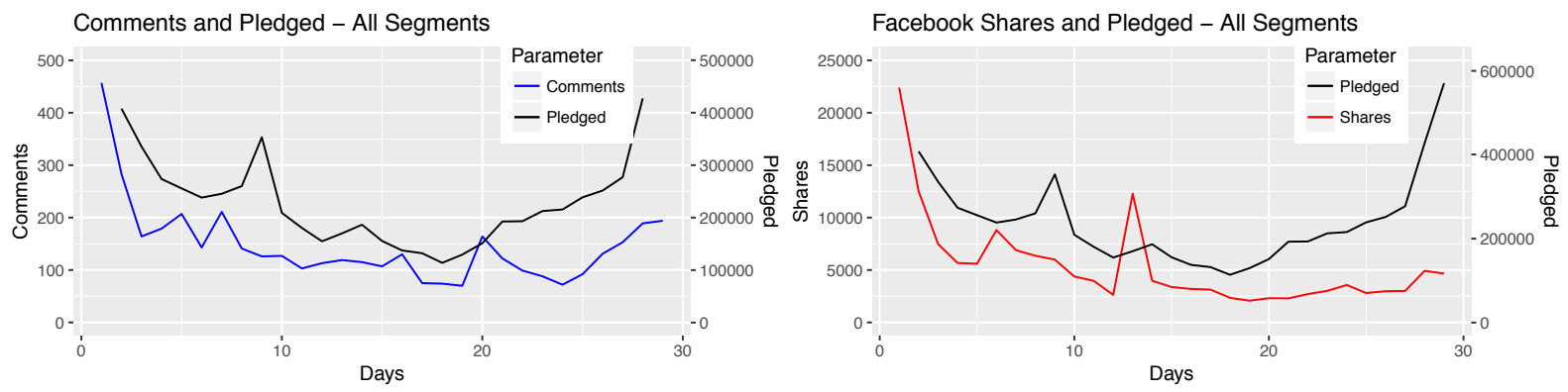